\title{
НЕКОТОРЫЕ МИНЕРАЛОГИЧЕСКИЕ АСПЕКТЫ ТЛ-ДАТИРО- ВАНИЯ И ПРОБЛЕМЫ ПОДГОТОВКИ ОБРАЗЦОВ
}

Методика термолюминесцентного (ТЛ) датирования четвертичных отложений предъявляет довольно высокие требования к лабораторной подготовке датируемого материала. Это связано с тем, что датируют на основе ТЛ-свойств конкретного минерала (кварц, полевой шпат), а также с тем, что методика ТЛ-датирования т. н. крупной фракции (размер зерен более 0,05 мм, иногда до 0,5 мм) требует удаления с поверхности и из трещин зерен слоя не менее 0,02 мм. Последнее неизбежно, чтобы избавиться от продуктов выветривания и влияния $\alpha$-компонента внешней природной (радиоактивной) дозы на измеряемую ТЛ. По мнению некоторых исследователей, этот компонент составляет до $80 \%$ из общей внешней дозы, но методически его трудно определить.

В Институте геологии АН ЭССР для датирования четвертичных отложений различного генезиса используют кварц (КВ) (Хютт и др., 1977, и др.) и калиевые полевые шпаты (КПШ). Размер ситовой фракции обычно $0,1-0,16$, реже $0,1-0,3$ мм; плотностная фракция (@) составляет

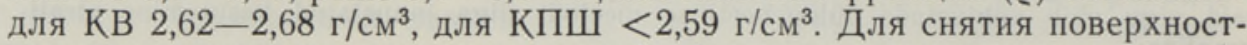
ного слоя и удаления из плотностной фракции лишних минералов (в основном карбонатов, плагиоклаз, слюд) используют обработку в кислотах $(\mathrm{HCl}$ и $\mathrm{HF}$ в разных концентрациях) с одновременным или последующим воздействованием ультразвука. При обилии слюд дополнительно применяется магнитная сепарация, но, к сожалению, из наших проб в магнитную фракцию со слюдами иногда выходил и более чистый КПШ (данные оптической микроскопии).

В последующем нам хотелось бы обратить внимание исследователей на некоторые проблемы, связанные с качеством подготовления проб для ТЛ-измерения. Предполагаем, что с ними следует считаться во избежание ошибок при датировании.

1. Отверстия большинства сит квадратные, а зерна минералов различной конфигурации, даже в хорошо окатанном материале несколько эллипсоидальны. Значит, размер многих зерен просеянной фракции крупнее стандартного диаметра отверстия сита и их средний размер повышен, даже если сита качественные. Так, во фракциях $>0,1$ мм размер зерен в среднем на 0,03 мм больше среднего по стандарту (рис. 1, табл. 1).
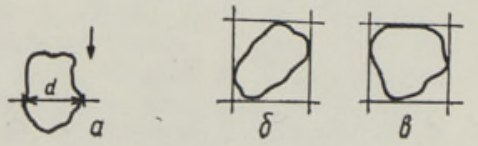

Рис. 1. Примеры истннного сн-
тового диаметра зерен в про-
сеянных пробах: $a-$ внд сбо-
ку; $6,8-$ виды сверху.

2. Растворение поверхностного слоя при обработке кислотой зависит не только от состава минеральных зерен кварца или полевых шпатов (ПШ), но и от генезиса минералов, выветрелости, размеров и конфигурации зерен (табл. 3,4$)$. Поэтому, особенно при наличии выветривания следует качество приготовленного материала проверять под микроско- 
Различие стандартного и действительного ситового размера проб кварца (определено под микроскопом, увел. $\times 320$ ), мм

\begin{tabular}{c|c|c|c|c}
\hline \multirow{2}{*}{$\begin{array}{c}\text { Размер фракции } \\
\text { (по стандарту } \\
\text { сита) }\end{array}$} & $\begin{array}{c}\text { Средняя ширина } \\
(\bar{x}) \text { отверстий } \\
\text { сита }( \pm 5 \%)\end{array}$ & \multicolumn{3}{|c}{$\begin{array}{c}\text { Ситовый диаметр зерен кварца в } \\
\text { просеянной фракции }\end{array}$} \\
\cline { 3 - 5 } & 0,1 & $x_{\text {мин }}$ & $x_{\text {макс }}$ & $\bar{x}$ \\
\hline $0,1-0,125$ & 0,125 & 0,124 & 0,163 & 0,141 \\
$0,125-0,16$ & 0,16 & 0,157 & 0,208 & 0,180 \\
$0,16-0,2$ & 0,2 & 0,186 & 0,260 & 0,220 \\
$0,2-0,25$ & 0,25 & 0,210 & 0,301 & 0,256
\end{tabular}

Таблица 2

Влияние обработки кислотой на размер зерен кварца в просеянных фракциях песка (измерено под микроскопом), мм

\begin{tabular}{|c|c|c|c|}
\hline \multirow[t]{2}{*}{ Размер фракции } & \multicolumn{2}{|c|}{$\begin{array}{l}\text { Ситовый диаметр зерен } \\
\frac{x_{\text {мин }}-x_{\text {макс }}}{\bar{x}}\end{array}$} & \multirow{2}{*}{$\begin{array}{l}\text { Уменьшение } \\
\text { диаметра } \\
\text { зерен }(\bar{x})\end{array}$} \\
\hline & до обработки & 1 ч в $\mathrm{HF}_{\text {конц }}$ & \\
\hline $0,1-0,125$ & $\frac{0,124-0,163}{0,141}$ & $\frac{0,105-0,143}{0,121}$ & 0,02 \\
\hline $0,125-0,16$ & $\frac{0,157-0,208}{0,179}$ & $\frac{0,126-0,203}{0,165}$ & 0,014 \\
\hline $0,2-0,25$ & $\frac{0,210-0,301}{0,257}$ & $\frac{0,191-0,285}{0,251}$ & 0,006 \\
\hline
\end{tabular}

таблица 3

Влияние кислотной обработки на массу кварца

\begin{tabular}{|c|c|c|c|}
\hline \multirow{2}{*}{$\begin{array}{l}\text { Размер фракции, } \\
\text { мм }\end{array}$} & \multirow{2}{*}{$\begin{array}{c}\text { Расчетная остаточная } \\
\text { масса, \% от исход- } \\
\text { ного* }\end{array}$} & \multicolumn{2}{|c|}{$\begin{array}{c}\text { Масса после обработки, \% от } \\
\text { исходного }\end{array}$} \\
\hline & & 1 ч в $\mathrm{HF}_{\text {конц }}$ & 1,5 ч в $\mathrm{HF}_{\text {конц }}$ \\
\hline $0,1-0,125$ & 30 & 44 & 33 \\
\hline $0,16-0,2$ & 47 & 67 & 47 \\
\hline $0,25-0,315$ & 63 & 72 & 55 \\
\hline
\end{tabular}

* По формуле шара, при уменьшении радиуса на 0,02 мм, без учета различий в растворимости и т. п. 
Влияние кислотной обработки на массу КПШ

\begin{tabular}{l|c|c|c|c}
\hline \multirow{2}{*}{\begin{tabular}{c} 
мазмер фракцин, \\
\cline { 2 - 4 }
\end{tabular}} & до обработки & $\begin{array}{c}\text { после обработки } \\
\text { в } 10 \% \text {-ной HF }\end{array}$ & $\begin{array}{c}\text { Время } \\
\text { обработки, } \\
\text { мнн }\end{array}$ & $\begin{array}{c}\text { Остаток, } \\
\%\end{array}$ \\
\hline $0,1-0,16$ & 1,39 & 0,80 & 15 & 58 \\
$0,16-0,25$ & 2,12 & 1,43 & 15 & 68 \\
$0,1-0,16$ & 1,48 & 0,83 & 15 & 56 \\
$0,16-0,25$ & 2,45 & 0,69 & 15 & 72 \\
$0,1-0,16$ & 1,90 & 1,40 & 10 & 74 \\
$0,16-0,25$ & 4,66 & 3,87 & 10 & 71 \\
$0,1-0,3$ & 0,95 & 0,68 & 5 & 45 \\
$0,1-0,3$ & 0,95 & 0,42 & +10 &
\end{tabular}

пом, лучше всего при помощи микрометра (табл. 2). Теоретический коэффициент потери массы (Сарапик, 1981) является здесь только т. н. минимальным определителем, который, например, не указывает на полное растворение зерен плагиоклаза в пробе с кварцом и т. д. Нужно также учесть, что процесс очищения может давать различные результаты даже при одинаковом режиме обработки (рис. 2). О влиянии кислот на минеральный состав и ТЛ-свойства можно судить и по опыту с пробой, теоретически состоящей только из КПШ (табл. 5, рис. 3). Подчеркиваем, что эти данные относятся к конкретному природному образцу и их нельзя автоматически переносить на все образцы ПШ с $\varrho<2,59$.

a

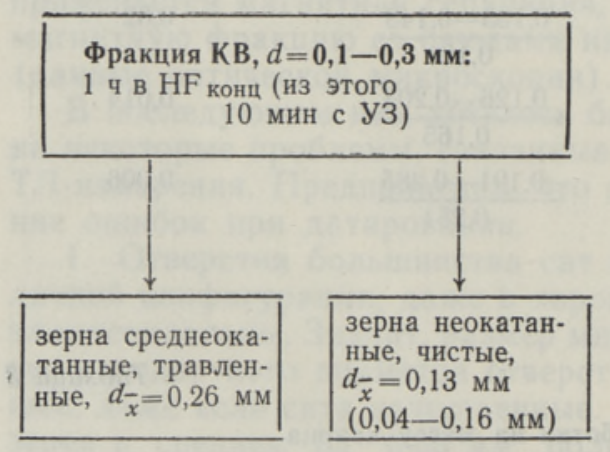

Рис. 2. Влияние $\mathrm{HF}$ и ультразвука (УЗ) на отдельные пробы: $a$ - фракция кварца (КВ) с

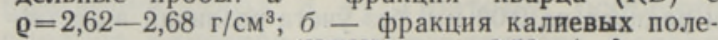

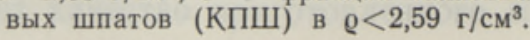

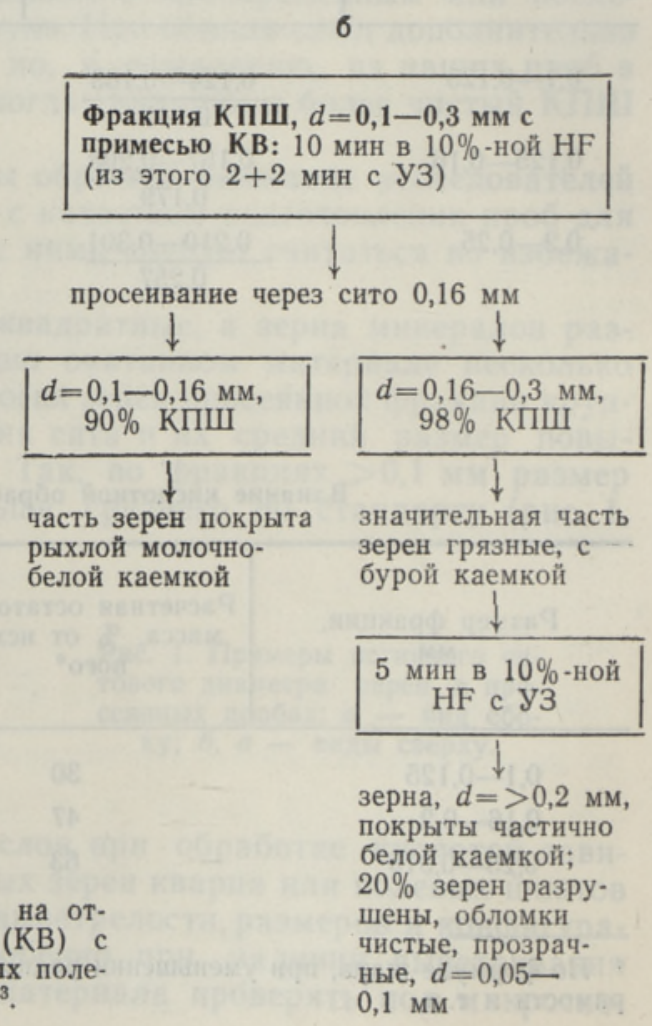


Изменение минерального соста丿ва проб̆ при об̆работке в НF $\left(0<2,59 \mathrm{r} / \mathrm{cm}^{3}\right)$

\begin{tabular}{|c|c|c|c|c|c|c|}
\hline \multirow[b]{2}{*}{ Режим обработки } & \multicolumn{5}{|c|}{ Минеральный состав, \%* } & \multirow{2}{*}{$\begin{array}{l}\text { Индекс } \\
\text { кривой } \\
\text { ТЛ на } \\
\text { рис. } 3\end{array}$} \\
\hline & $\begin{array}{l}\text { КПШ } \\
\mathrm{Ng}<1,527\end{array}$ & $\begin{array}{c}\text { K-Na ПШ } \\
\text { (+альбит) }\end{array}$ & $\begin{array}{c}\text { Плагио- } \\
\text { клазы № } \\
\text { № } 10-30\end{array}$ & KB & $\begin{array}{l}\text { Сильно } \\
\text { вывет- } \\
\text { релые }\end{array}$ & \\
\hline
\end{tabular}

20 мин в $5 \%$-ной НF 20 мин в $10 \%$-ной $\mathrm{HF}$ 20 мин в $15 \%$-ной $\mathrm{HF}$ 5 мин в $20 \%$-ной HF Контроль (без HF)

$\begin{array}{ccc}62 & 1,9 & 0 \\ 63 & 1,3 & 0 \\ 91 & 2,7 & 0,6 \\ 48 & 0,5 & 0 \\ 49 & 3,8 & 10\end{array}$

28
26
4,8
51
31

\section{8,1}

9,6

0,9

0,9

5,9

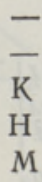

* $\pm 1-2 \%$.

Рис. 3. ТЛ-кривые образцов после обработки в HF (см. табл. 5).

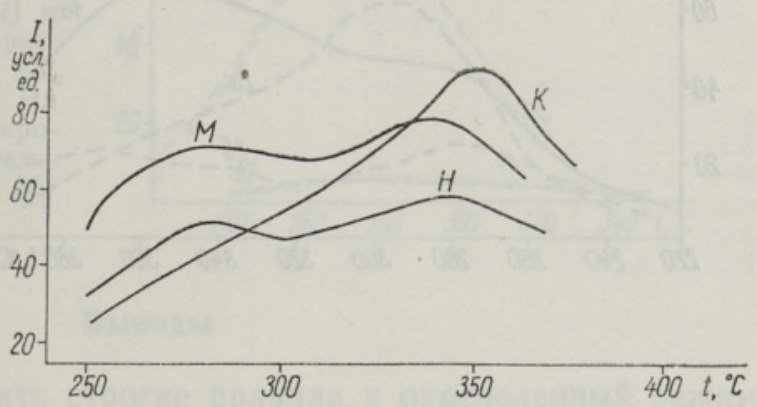

таблица 6

Состав природных полевых шпатов, определенный с применением различных методик в целях оценки содержания калиевого компонента, \%

\begin{tabular}{|c|c|c|c|c|c|c|c|c|c|c|c|}
\hline \multirow{3}{*}{$\begin{array}{c}\text { Образец и } \\
\text { место- } \\
\text { нахождение }\end{array}$} & \multicolumn{7}{|c|}{ Минералогический состав } & \multirow{2}{*}{\multicolumn{2}{|c|}{$\begin{array}{c}\text { Химический } \\
\text { состав } \\
( \pm 0,5 \%)\end{array}$}} & \multirow{2}{*}{\multicolumn{2}{|c|}{$\begin{array}{l}\text { Компонент- } \\
\text { ный состав }\end{array}$}} \\
\hline & \multicolumn{4}{|c|}{$\begin{array}{l}\text { Оптическая микроскопия } \\
( \pm 1-5 \%)\end{array}$} & \multicolumn{3}{|c|}{$\begin{array}{c}\text { Рентгеноструктурный } \\
\text { анализ }( \pm 10 \%)\end{array}$} & & & & \\
\hline & 早 & $\begin{array}{l}\text { 前 } \\
\text { Z̃ } \\
\vdots \\
\vdots\end{array}$ & 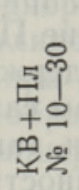 & 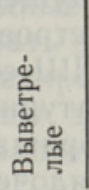 & 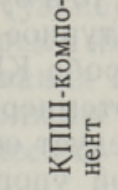 & 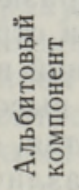 & $\stackrel{m}{\underline{y}}$ & Oู & $\begin{array}{l}0 \\
\text { Z } \\
\text { Z }\end{array}$ & 旾 & $\begin{array}{l}\text { 章 } \\
\text { 点 }\end{array}$ \\
\hline
\end{tabular}

Песок $\mathrm{Q}_{4}$

\section{(Эстония)}

,

Песок $Q_{3}$

(Акджар)

$$
\text { , }
$$

Ортоклаз

Мнкроклин

Санидин

Альбит

$$
\begin{array}{rrrrrrrrrrr}
79 & 12,6 & 6,3 & 2,4 & - & - & - & 12,5 & 0,62 & 73 & 5,2 \\
71 & 1,4 & 25 & 2,1 & - & - & - & 14,1 & - & 82 & - \\
73 & 6,2 & 17,5 & 3,3 & - & - & - & 11,8 & - & 69 & - \\
75 & 3,0 & 21 & 0,7 & 85 & 15 & 0 & 9,3 & 1,6 & 54 & 13,3 \\
90 & 1,0 & 8,5 & 0,5 & 80\left(\mathrm{c} \mathrm{Na}^{+}\right) & 20 & 0 & 13,0 & 1,0 & 75 & 8,5 \\
\multicolumn{8}{c}{\text { Дробленные монокристаллы }}
\end{array}
$$

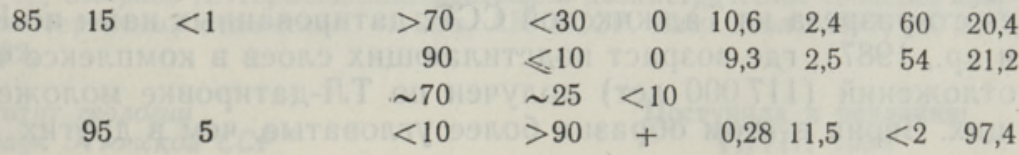


3. Наш опыт показывает, чт̄o получить из четвертичных отложений пробу, содержащую только чистокалиевый ПШ $\left(\mathrm{K}_{2} \mathrm{O}\right.$ теоретически около $17 \%$ ), в практике, к сожалению, невозможно (табл. 6). Однако в некоторых случаях учитывание содержания калия в пробе методически неизбежно. Так, из-за сложного строения природных ПШ, при ТЛ-датировании по КПШ необходимо определять в каждом образце не только минералогические показатели, но и элементный и структурный составы.

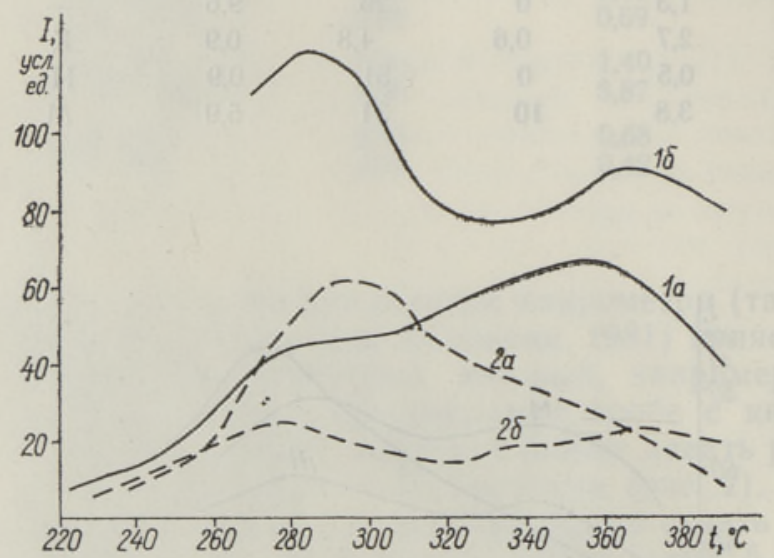

Рис. 4. ТЛ-кривые санидина (1) и альбита (2). Материал природных монокристаллов, $a-$ фракция $0,1-0,16$ мм, б- обработан в $10 \%$-ной HF. Состав см. табл. 6.

4. Изучение ТЛ-свойств различных образцов показало, что иногда кислотная обработка значительно влияет на ТЛ-свойства материала (рис. 3,4$)$. Даже при материале из большого природного монокристалла (музейные образцы), где нет влияния внешнего $\alpha$-излучения на ТЛ, действие кислоты может оказаться значительным (рис. 4). По данным минералогического анализа, состав образца при обработке существенно не изменялся. Правда, по теоретическим представлениям природные монокристаллы по составу не очень однородны, но по номенклатуре ПШ соответствуют своему названию (Трегер, 1980, табл. 6).

Если эти, пока предварительные данные все-же найдут подтверждение на примере других образцов, то в будущем, при датировании по КПШ следовало бы учитывать и структурное строение ПШ (рис. 5). Особенно в том случае, если основной в пробе КПШ содержит много альбитового компонента или является высокотемпературным санидином. Так как ТЛсвойства КПШ различаются, следует обращать также больше внимания на содержание КПШ с различной упорядоченностью структуры (ортоклаз или микроклин). Свечение микроклина (триклинный КПШ) в данном случае, например, в 15 раз слабее свечения ортоклаза (моноклинный КПШ), хотя их химический состав фактически одинаков. Свечение же моноклинного КПШ санидина, правда, с бо́льшим содержанием $\mathrm{Na}$ компонента примеси кварца, около 30 раз слабее свечения микроклина.

Одна из причин получения ошибочных датировок кроется видимо в том, что фракция КПШ четвертичных отложений в большинстве случаев является смесью минералов разных магматических пород. В качестве примера здесь можно привести данные о возрасте отложений Акджарского разреза из Таджикской ССР, датированных нами по КПШ (Варес и др., 1987), где возраст подстилающих слоев в комплексе четвертичных отложений (117000 лет) получен по ТЛ-датировке моложе надстилающих. Зерна в этом образце более угловатые, чем в других образцах из 
этого разреза, некоторые из них с мозаичным погасанием. По данным минералогического анализа фракция КПШ содержит около $7 \%$ двойникованных по альбитовому закону зерен. По рентгеноструктурному анализу ортоклаз содержит около $20 \%$ изоморфного $\mathrm{Na}$ (табл. 6). $\mathrm{HF}$ воздействовал на этот материал сильнее, зерна уменьшились почти вдвое.

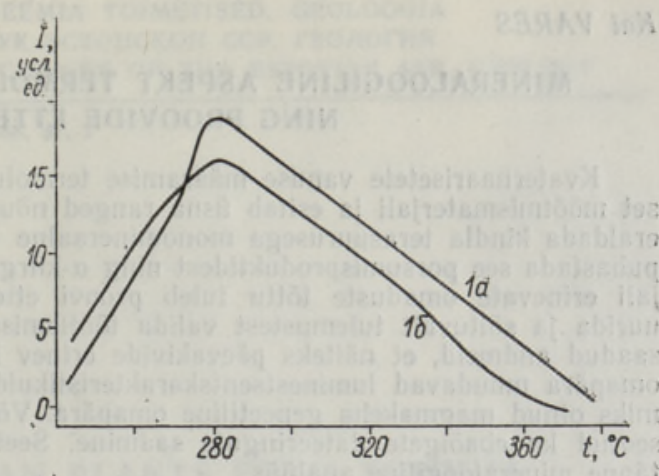

Рнс. 5. ТЛ-кривые микроклина (1) и ортоклаза (2). Материал монокристалла: $a-$ фракция $0,1-0,16$ мм, 6 - обработан в $10 \%$-ной HF. На нижнем графике кривые ТЛ микроклина (1a и 1б) даны в сравнительном масштабе с ортоклазом ( $2 a$ и $2 б)$ по интенсивности.

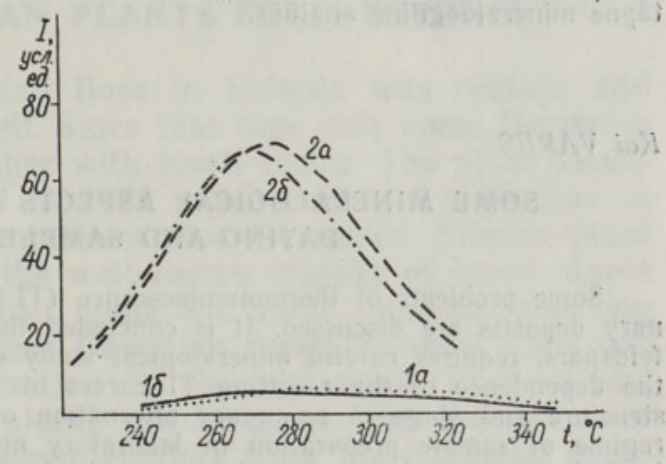

\section{Выводы}

1. Невозможно установить строгие правила и определенный режим приготовления препаратов для ТЛ-датирования, особенно для ПШ. Это затруднено тем, что природный материал часто не обрабатывается согласно теоретическим представлениям. Каждый образец надо изучать отдельно и выбирать наиболее подходящий режим уже в ходе подготовки проб.

2. Режим обработки песчаных фракций кварца ( 1 ч в $\left.\mathrm{HF}_{\text {конц }}\right)$, применяемый в настоящее время во многих лабораториях мира, не гарантирует избавления от влияния $\alpha$-излучения даже при содействии с ультразвуком потому, что при крупности зерен $>0,15$ мм толщина растворенного слоя не более 0,01 мм. По той же причине целесообразнее использовать более однородные (узкие) гранулометрические фракции и соответственно отрегулировать время кислотной обработки.

3. Во избежание при датировании ошибок от неоднородности минерального состава все образцы должны контролироваться не менее чем двумя способами - минералогическим и химическим.

\section{ЛИТЕРАТ У РА}

Варес К. Х., Кошкина А. А., Сусликов В. Н., Хютт Г. И. Результаты термолюминесцентного датирования плейстоценовых отложений Акджарского разреза (Восточный Памир). - В сб.: Геохронология четвертичного периода. М., 1987 (в печати).

Сарапик Ю. Некоторые мннералогические аспекты термолюмннесцентного (ТЛ) датирования по кварцу. - В сб.: Новые методы в геологии Эстонин. Таллин, 1981, $99-115$.

Tрегер B. E. Оптическое определение породообразующих минералов. М., 1980.

Хютт $Г$., Варес К., Смирнов А. Термолюминесцентные и дозиметрические свойства кварца из четвертичных отложений. - Изв. АН ЭССР. Хим. Геол., 1977, 26, № 4, $276-282$.

\section{Ннститут геологии \\ Академии наук Эстонской ССР}

Поступила в редакцию 11/VIII 1986 


\section{MINERALOOGILINE ASPEKT TERMOLUMINESTSENTSDATEERIMISÉL NING PROOVIDE ETTEVALMISTAMINE}

Kvaternaarisetete vanuse määramise termoluminestsentsmeetod nõuab monomineraalset mõõtmismaterjali ja esitab üsna ranged nõuded proovide ettevalmistamisele. On vaja eraldada kindla terasuurusega monomineraalne (kvarts, kaaliumpäevakivid) fraktsioon ja puhastada see porsumisproduktidest ning $\alpha$-kiirgusest mõjutatud kihist. Loodusliku materjali erinevate omaduste tõttu tuleb proovi ettevalmistamisel materjali mikroskoobi all uurida ja sõltuvalt tulemustest valida töötlemisrežiimid raskes vedelikus ja hapetes. On saadud andmeid, et näiteks päevakivide erinev kaaliumisisaldus ja ka lihtsalt struktuuri omapära muudavad luminestsentskarakteristikuid, samuti võib seda põhjustada lähtekivimiks olnud magmakeha geneetiline omapära. Võimalik, et kivimite nende omadustega on seotud ka ebaôigete dateeringute saamine. Seetõttu on soovitatav proovide võimalikult täpne mineraloogiline analüüs.

\section{Kai VARES}

\section{SOME MINERALOGICAL ASPECTS OF THERMOLUMINESCENCE DATING AND SAMPLE PREPARATION}

Some problems of thermoluminescence (TL) dating of sandy fraction from Quaternary deposits are discussed. It is concluded that the TL dating method, especially for feldspars, requires careful mineralogical study of the prepared material. This is due to the dependence of the resulting TL-curves of the samples upon the genesis, chemical structure and stage of secondary alternation of mineral grains. So the technique and regime of sample preparation in laboratory must be chosen separately for each geological sample to get really adequate probes for TL measuring. 